\title{
Reduced susceptibility to selected synthetic pyrethroids in urban malaria vector Anopheles stephensi: a case study in Mangalore city, South India
}

\author{
Satyanarayan Tiwari1, Susanta K Ghosh*1, Vijay P Ojha', Aditya P Dash2,3 and Kamaraju Raghavendra²
}

\begin{abstract}
Background: Synthetic pyrethroids are potent insecticides most commonly used in the vector control programme. These are applied for indoor residual sprays, space sprays and in impregnated bed nets. Resistance reduces the efficacy of insecticides. Thus, the susceptibility status of the target vector(s) is monitored routinely to select the effective ones. A study was undertaken in a malaria endemic coastal city Mangalore, Karnataka, South India, against the known malaria vector Anopheles stephensi.

Methods: The susceptibility status was assessed at diagnostic doses of DDT (4\%), malathion (5\%), deltamethrin (0.05\%), cyfluthrin (0.15\%), alphacypermethrin (0.10\%), lambdacyhalothrin (0.05\%) and permethrin (0.75\%) using the standard WHO tube test method during October/November 2006.

Results: Anopheles stephensi was resistant to malathion by $54.9 \%$, but tolerant to deltamethrin by $86.1 \%$, cyfluthrin 95.5\% and alphacypermethrin 90.6\%, whereas it was susceptible to DDT by $98.1 \%$, lambdacyhalothrin $98.6 \%$ and permethrin $100.0 \%$, respectively. The $\mathrm{KDT}_{50}$ and $\mathrm{KDT}_{95}$ values for these insecticides also showed the similar responses.

Conclusion: Susceptibility of An. stephensi to DDT is an important finding as this has never been used in Mangalore city, whereas its rural counterpart Anopheles culicifacies is widely resistant to this insecticide. The study explores the selection and rotation of the appropriate insecticide molecule even within the same group for effective vector management.
\end{abstract}

\section{Background}

In recent years, there are many options and strategies to combat diseases transmitted by insect vectors. Insecticides still remain the mainstay of vector control programmes [1]. Synthetic pyrethroids are extensively being used for indoor residual sprays, space sprays and in impregnated bed nets. These are highly effective, if optimally applied, but resistance to these chemicals reduces their impact [2]. Tube and cone bioassays on sprayed surfaces and substrates to monitor the susceptibility status of the target vector(s) are effective tools to assess the efficacy of insecticides. The present work was carried out in

*Correspondence: ghoshmrc@vsnl.net

${ }^{1}$ National Institute of Malaria Research, ICMR Complex, Poojanahalli, Kannamangala Post, Devanahalli, Bangalore, 562110, Karnataka, India Full list of author information is available at the end of the article
Mangalore city, where malaria has been a serious public health problem for more than one and half decades [3]. The vector control strategies adopted to curtail malaria transmission in urban settings are anti-larval operations, whereas indoor residual spraying (IRS) is not recommended. However, personal protection measure with insecticide-treated nets (ITNs), especially with synthetic pyrethroids, has been advocated [4].

Recently under the World Bank-aided Enhanced Malaria Control Programme (EMCP), ITNs have been advocated to control malaria in rural areas. To assess the operational feasibility of ITNs in malaria control in urban areas, a study on long-lasting insecticide-treated nets (LLINs) with alphacypermethrin was carried out in the city from October 2006 to August 2007. Baseline data on susceptibility status of Anopheles stephensi to different 
insecticides were collected prior to the LLIN trial to explore an appropriate insecticide molecule.

\section{Methods}

\section{Study area}

Mangalore city $\left(12^{\circ} 55^{\prime} \mathrm{LN} 74^{\circ} 47^{\prime} \mathrm{LE}\right.$, average elevation of $22 \mathrm{~m}$ asl) is situated on the Western coast of Arabian Sea in Karnataka, South India. It has 494,629 inhabitants living in an area of $132.45 \mathrm{~km}^{2}$. The climate is tropical with dry season (January-May), monsoon (June-August) and post-monsoon (September-December). Average temperature ranges between 16 and $35^{\circ} \mathrm{C}$, average relative humidity around $85 \%$, and $4400 \mathrm{~mm}$ of average annual rainfall. It is a port city with many activities that attract labour migrants (8-12\% of urban population) engaged in construction related works. The recorded literacy rate is $83 \%$. The city has 60 municipal wards, and the health services are provided by five municipal corporation hospitals and two government hospitals, besides five local medical colleges. In this city, the annual parasite incidence (API; cases per 1,000 population annually) varies from 1.2 to 3.1 , and contributes nearly $15-20 \%$ of the total malaria cases with few deaths annually in Karnataka, and nearly $0.2-0.8 \%$ in India [3]. Anopheles stephensi is the main malaria vector that preferably breeds in wells, over head tanks, cement tanks, fountains and also in masonry tanks, curing waters in construction sites [5]. Active transmission is recorded during the post-monsoon months, and recently this insect vector has been incriminated in this city [5]. The vector control strategies adopted to curtail malaria transmission are anti-larval operations using chemical larvicides mainly temephos and fenthion (both organophosphorus compounds), indoor pyrethrum spray, outdoor fogging with malathion and synthetic pyrethroids especially deltamethrin and cyfluthrin. Larvivorous fish in wells, fountains, water storage cement tanks, masonry water tanks at construction sites, are additionally applied.

\section{Insecticide susceptibility tests}

Susceptibility of insecticides by tube test method was carried out according to the standard WHO procedure during October/November 2006 [6-8] with WHO-supplied insecticide-impregnated papers as per diagnostic doses, DDT (4\%), malathion (5\%), deltamethrin $(0.05 \%)$, cyfluthrin $(0.15 \%)$, alphacypermethrin $(0.10 \%)$, lambdacyhalothrin $(0.05 \%)$ and permethrin $(0.75 \%)$. Immature stages of anopheles mosquitoes collected from three sites, Nanthoor, Bejai and Balmatta in the city (Figure 1), brought live to the laboratory, reared to adults. Emerged An. stephensi females were fed on mice blood and full-fed mosquitoes were exposed to the insecticide-impregnated papers for $1 \mathrm{~h}$. Experiments were conducted with a minimum of three replicates with matched controls for each

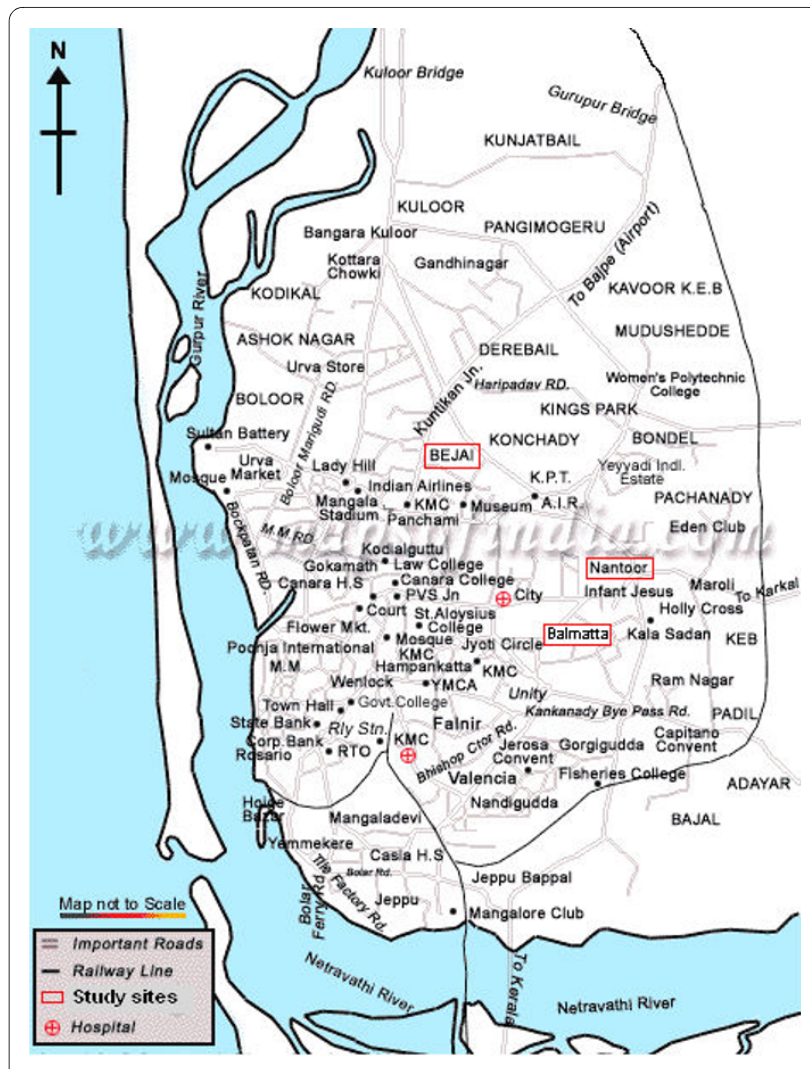

Figure 1 Map showing the study sites in Mangalore City, Karnataka, South India.

insecticide in a room maintaining temperature at $27 \pm$ $2^{\circ} \mathrm{C}$ and $80 \%$ relative humidity. The knockdown effect of each insecticide was recorded every 10 minutes over the 1-h exposure period. Exposed mosquitoes were then transferred to a recovery tube and provided with $10 \%$ glucose solution. Final mortality was recorded after $24 \mathrm{~h}$ of holding time in experimental and control tubes. Mortality in control between 5 and $20 \%$ was corrected with Abbott's formula [9] and expressed as corrected percent mortality.

Corrected $\%$ mortality $=\frac{\% \text { Observed mortality }-\% \text { Control mortality }}{100-\% \text { Control mortality }} \times 100$

\section{Data analysis}

Data were analysed using VassarStats software [10]. Fifty and $95 \%$ knockdown times $\left(\mathrm{KDT}_{50}\right.$ and $\left.\mathrm{KDT}_{95}\right)$ were estimated by means of a log-time probit model using the Ldp line ${ }^{\mathrm{R}}$ software $[11,12]$.

\section{Results}

The result of bioassays is summarized in Table 1. As per the WHO criteria, mortality $<80 \%$ is considered to be resistant, $80-98 \%$ as tolerant (evaluation required) and $>$ $98 \%$ as susceptible [6]. Accordingly, An. stephensi in Man- 
Table 1: Susceptibility status of An. stephensi (October/November, 2006) to standard doses of insecticides (7 such) following WHO methods* (1975) in Mangalore city, Karnataka, South India

\begin{tabular}{|c|c|c|c|c|c|c|c|c|c|}
\hline \multirow{2}{*}{$\begin{array}{l}\text { Diagnostic insecticide } \\
\text { dose on impregnated } \\
\text { papers\# }\end{array}$} & \multicolumn{2}{|c|}{ Mosquitoes exposed (n) } & \multicolumn{2}{|c|}{$\begin{array}{l}\text { Dead mosquitoes } \\
\text { after } 24 \mathrm{~h} \text { of } \\
\text { exposure (n) }\end{array}$} & \multicolumn{2}{|c|}{ Mortality after $24 \mathrm{~h}$ of exposure (\%) } & \multirow[t]{2}{*}{$\begin{array}{l}\text { Corrected } \\
\text { mortality (\%)§ }\end{array}$} & \multirow[t]{2}{*}{ KDT50 (CL) } & \multirow[t]{2}{*}{ KDT95 (CL) } \\
\hline & Expt & Cont & Expt & Cont & Expt $(95 \% \mathrm{Cl})$ & Cont $(95 \% \mathrm{CI})$ & & & \\
\hline DDT 4\% & 60 & 60 & 59 & 7 & $98.3(92.99-103.65)$ & $11.65(6.33-16.89)$ & $98.1(92.95-103.19)$ & $19.24(18.87-21.48)$ & $55.67(47.78-68.50)$ \\
\hline Malathion 5\% & 106 & 106 & 65 & 15 & $45.36(13.98-76.74)$ & $14.06(10.93-17.19)$ & $54.9(46.74-72.42)$ & $765.82^{\ddagger}$ & $34147.10^{\ddagger}$ \\
\hline Deltamethrin $0.05 \%$ & 72 & 72 & 63 & 7 & $86.62(69.78-103.46)$ & $9.62(6.24-3.00)$ & $86.1(76.38-103.93)$ & $37.33(35.02-39.88)$ & $72.73(64.96-85.11)$ \\
\hline Cyfluthrin $0.15 \%$ & 77 & 57 & 74 & 8 & 95.57 (78.5-109.64) & $13.93(9.35-18.51)$ & $95.5(79.00-110.94)$ & $31.74(29.50-33.96$ & $69.74(62.03-81.56)$ \\
\hline Alpha-cypermethrin 10\% & 68 & 50 & 62 & 3 & $91.2(86.27-96.13)$ & $6.03(4.52-7.54)$ & $90.6(85.34-95.90)$ & $30.33(27.69-33.12)$ & $83.26(70.79-104.26)$ \\
\hline Lambda-cyhalothrin $0.05 \%$ & 80 & 60 & 79 & 5 & $98.75(94.78-102.72)$ & $8.33(1.17-15.49)$ & $98.6(94.10-103.05)$ & $19.20(17.34-20.97)$ & $50.42(44.99-58.17)$ \\
\hline Permethrin $0.75 \%$ & 77 & 57 & 77 & 3 & $100.0(100.0-100.0)$ & $5.3(4.04-6.59)$ & $100.0(100.0-100.0)$ & $16.83(14.87-18.67)$ & $47.93(41.35-58.52)$ \\
\hline
\end{tabular}

${ }^{*}$ Mortality recorded < $80 \%$ considered resistant, $80-98 \%$ tolerant (evaluation required), while $>98 \%$ as sensitive.

\#Supplied by WHO

${ }^{\S}$ Corrected mortality was calculated following Abott's formula (1925).

FConfidence limit could not be calculated due to large g values.

Exp: Experimental; Cont: Control; Cl: Confidence interval; $\mathrm{CL}$ : Confidence limit 
galore city was resistant to malathion, having $54.9 \%$ (95\% CI: 46.74-72.42) mortality, but susceptible to DDT, lambdacyhalothrin and permethrin showing mortalities of 98.1\% (95\% CI: 92.95-103.19), 98.6\% (95\% CI: 94.10103.05 ) and $100 \%$ respectively. Mortalities recorded to deltamethrin, cyfluthrin and alphacypermethrin were 86.1\% (95\% CI: 76.38-103.93), 95.5\% (95\% CI: 79.00$110.94)$ and $90.6 \%$ (95\% CI: 85.34-95.90), respectively, indicating tolerance.

The knockdown effect determined over a 1-h period indicated that, $\mathrm{KDT}_{50}$ and $\mathrm{KDT}_{95}$ for malathion was the highest among the seven insecticides tested. These values were also higher for deltamethrin, cyfluthrin and alphacypermethrin than DDT, lambdacyhalothrin and permethrin (Table 1).

\section{Discussion}

Resistance to both DDT and malathion in An. stephensi was reported earlier from the rural area of Harayana [13], from urban areas of Goa [14], and Delhi [15]. In Bikaner district of Rajasthan, it was reported resistant to DDT and tolerant to both malathion and permethrin [16]. The present study showed that An. stephensi is susceptible to DDT and permethrin, whereas it is resistant to malathion. The $\mathrm{KDT}_{50}$ and $\mathrm{KDT}_{95}$ values were also maximum for malathion and minimum for permethrin, suggesting that the knockdown resistance mechanism could be operating in the mosquito population, as has been demonstrated in lab in An. stephensi with deltamethrin [17].

In Mangalore city, the possible reason for the development of resistance in An. stephensi to malathion and low mortalities in deltamethrin and cyfluthrin could be attributed to selective pressure from fogging, IRS including anti-larval operations with these molecules for more than a decade. Tolerance in alphacypermethrin could be the consequence of cross-resistance among synthetic pyrethroid molecules exhibiting similar resistance mechanism $[17,18]$.

\section{Conclusion}

Susceptibility of An. stephensi to DDT is an important finding, whereas its rural counterpart Anopheles culicifacies is widely resistant to this insecticide [18]. The reason could be that this molecule has never been used in Mangalore city [3], thus maintaining a status of susceptibility in the area in absence of selection pressure.

In the ITN programme, only synthetic pyrethroids are being used for impregnation of nets. A recent report indicated the evolution of resistance in An. gambiae to pyrethroids in Africa [2], and the reduced susceptibility of $A n$. stephensi to deltamethrin, cyfluthrin and alphacypermethrin in Mangalore city is a matter of concern. In view of the current scenario, emphasis could be given on other methods of vector control, preferably biocontrol with larvivorous fish and different formulations of biolarvicides especially Bacillus thuringiensis var. israelensis under the integrated vector management programme $[19,20]$. In Mangalore city, open dug wells are present in the courtyard almost in every house and these serve as major foci (ecological niche) for An. stephensi. The construction activities begin in the vicinity of such wells leads to profuse breeding of An. stephensi in the curing waters, masonry tanks and other water collection created during the activities. Immigrant labourers from malaria endemic areas act as reservoirs add to the problem immensely who reside near to these sites. The current application of fogging should be discontinued as these are not recommended for routine vector control programme [4]. Thus the malaria control operation in the city should focus alternatively on anti-larval strategies [4]. Fortnightly application of biolarvicides in the curing waters in the construction areas and introduction of larvivorous fish particularly Poecilia $[19,20]$ in all the breeding habitats especially in wells would be the best option for antilarval measures. Integrated vector management strategies specific to this urban setting need to be optimally used for its appropriate implementation.

\section{Competing interests \\ The authors declare that they have no competing interests.}

\section{Authors' contributions}

ST, SG and KR conceived and arranged the entire study. VPO assisted in conduction of the test in the field. APD reviewed and edited the paper. All authors helped write, read and approved the final manuscript.

\section{Acknowledgements}

To the staff of National Institute of Malaria Research (NIMR), Bangalore Centre for their technical assistance. To Dr. P.K. Kar, NIMR, Bangalore centre for reviewing and to Dr. Chaitali Ghosh, S.R. Nova Pvt. Ltd., Bangalore for editing the manuscript.

\section{Author Details}

'National Institute of Malaria Research, ICMR Complex, Poojanahalli, Kannamangala Post, Devanahalli, Bangalore, 562110, Karnataka, India, 2National Institute of Malaria Research, Sector 8, Dwarka, New Delhi, 110077, India and ${ }^{3}$ World Health Organization South East Asia Regional Office, Indra Prastha Marg, New Delhi, 110 002, India

Received: 29 March 2010 Accepted: 23 June 2010

Published: 23 June 2010

\section{References}

1. Devine GJ, Ogusuku E: Adaptability is key when monitoring insecticide resistance. Bull World Health Organ 2009, 87:887.

2. N'Guessan R, Corbel V, Akogbeto M, Rowland M: Reduced efficacy of insecticide-treated nets and indoor residual spraying for malaria control in pyrethroid resistance area, Benin. Emerg Infect Dis 2007 , 13:199-206

3. National Vector Borne Disease Control Programme (NVBDCP): Annual Reports on Malaria and other Vector Borne Diseases Directorate of Health and Family Welfare Services, Government of Karnataka, Bangalore; 2008.

4. National Vector Borne Disease Control Programme (NVBDCP): Operational Manual for Implementation of Malaria Control Programme. Directorate General of Health Services, Ministry of Health and Family Welfare, Government of India, New Delhi 2009 [http://nvbdcp.gov.in/ Doc/Malaria-Operational-Manual-2009.pdf]. 
5. Ghosh SK, Tiwari SN, Raghavendra K, Sathyanarayan TS, Dash AP Observations on sporozoite detection in naturally infected sibling species of the Anopheles culicifacies complex and variants of Anopheles stephensi in India. J Biosci 2008, 33:333-336.

6. WHO: Manual on practical entomology in malaria. Part II. Method and Techniques 1975.

7. WHO: Mimeographed document. WHOVBC/81 805 Geneva: World Health Organization; 1981:1-7.

8. Mittal PK, Adak T, Singh OP, Raghavendra K, Subbarao SK: Reduced susceptibility to deltamethrin in Anopheles culicifacies sensu lato, in Ramamnathapuram district, Tamil Nadu -- Selection of a pyrethroidresistant strain. Curr Sci 2002, 82:185-188.

9. Abbott WS: A method of computing the effectiveness of insecticide. $J$ Econ Entomol 1925, 18:265-267.

10. VassarStats statistical software website [http://faculty.vassar.edu/lowry/ VassarStats.html].

11. Log-time probit model software website [http://www.ehabsoft.com/ Idpline/].

12. Finney DJ: Probit Analysis 3rd edition. Cambridge University Press: Cambridge, UK; 1971.

13. Subbarao SK, Sharma VP, Vasantha K, Adak T: Effect of malaria spraying on four anopheline species and the development of resistance in Anopheles stephensi in Mandora, Harayana. Indian J Malariol 1994, 21:109-114.

14. Thavaselvam D, Kumar A, Sumodan PK: Insecticide susceptibility status of Anopheles stephensi, Culex quinquefasciatus and Aedes aegypti in Panaji, Goa. Indian J Malariol 1986, 23:65-67.

15. Sharma VP, Sharma GK, Ansari MA, Mittal PK, Razdan RK, Batra CP: Impact of malathion thermal fogging on mosquito population in Delhi and its place in malaria control. Indian J Malariol 1986, 23:65-67.

16. Bansal SK, Singh KV: Insecticide susceptibility status of some anophelines in district Bikaner, Rajasthan. Indian J Malario/ 1996, 33:1-6.

17. Gyathri V, Murthy PB: Reduced susceptibility to deltamethrin and $k d r$ mutation in An. stephensi Liston, a malaria vector in India. J Am Mosa Cont Assoc 2006, 22:678-688.

18. Dash AP, Adak T, Raghavendra K, Singh OP: The biology and control of malaria vectors in India. Curr Sci 2007, 92:1571-1578.

19. Ghosh SK, Dash AP: Larvivorous fish against malaria vectors: a new outlook. Trans R Soc Trop Med Hyg 2007, 101:1063-1064.

20. Tiwari SN, Ghosh SK, Mittal PK, Dash AP: Effectiveness of a granular formulation of Bacillus thuringiensis var. israelensis (Bti) against larvae of malaria vectors in laboratory and field conditions, India. VectorBorne Zoon Dis 2010, 10: Published online May 2010, ahead of print, DOl: 10.1089/vbz.2009.0197.

doi: $10.1186 / 1475-2875-9-179$

Cite this article as: Tiwari et al., Reduced susceptibility to selected synthetic pyrethroids in urban malaria vector Anopheles stephensi: a case study in Mangalore city, South India Malaria Journal 2010, 9:179

\section{Submit your next manuscript to BioMed Central} and take full advantage of:

- Convenient online submission

- Thorough peer review

- No space constraints or color figure charges

- Immediate publication on acceptance

- Inclusion in PubMed, CAS, Scopus and Google Scholar

- Research which is freely available for redistribution

Submit your manuscript at www.biomedcentral.com/submit
C Biomed Central 